\section{Choledocholithiasis - a practical approach from the endosonographer}

D. O’Toole, L. Palazzo

Service de Gatroentérologie, Hôpital Beaujon, Clichy 92118, Beaujon Hospital, University of Paris VII, Clichy, France

\section{Introduction}

The widespread availability of endoscopic ultrasound (EUS) has facilitated evaluation of the pancreas and extra-hepatic biliary system. EUS to date has been shown to be highly sensitive in the detection of both choledocholithiasis (especially in patients with small stones and non-dilated bile ducts) and gallbladder microlithiasis, however the use of this technique in relation to endoscopic retrograde cholangiography (ERCP) and laparoscopic surgery in gallstone disease remains somewhat confusing. EUS has the added advantage of accurately discriminating CBD obstruction due to choledocholithiasis and other causes such as small ampullary tumours, cholangiocarcinoma, benign extra-heaptic cholangitis, congenital bile duct or peri-ampullary abnormalities (which together account for $10-20 \%$ of cases of CBD obstruction in patients with suspicion of CBD stones). This review highlights technical aspects of examining the extra-hepatic biliary duct system and the clinical performance and results of EUS in this context and proposes strategies in relation to its use in association with ERCP and surgery in common clinical practice. The use of EUS in patients with a asymptomatic dilated common bile duct (CBD) is also discussed.

\section{Technical aspects}

Visualisation of the extra-hepatic bile ducts using EUS demands a systematic approach and is best performed under mild intravenous sedation with mizadolam and/or propofol. With the patient in the left lateral decubitus position the transducer is placed in the distal portion of the second segment of the duodenum and withdrawn to the ampullary region. Above the distal common bile duct (CBD) is seen along with the terminal portion of the main pancreatic duct (Fig.1). Slight proximal movements allow visualisation of the intra-pancreatic CBD which is often located close to water balloon; the latter may sometimes need to be deflated so as to not compress the CBD (Fig. 1a). The CBD and common hepatic duct (CHD) are examined in longitudinal sections (Fig. 2) as far proximally as the hepatic duct with the transducer in the genu superius and/or the duodenal bulb. The proximal duodenum also affords examination of the porta hepaticus with the cystic duct and the fundus and neck of the gallbladder. Positioning in the duodenal bulb yields access to the gallbladder and CBD from its origin in the hilum to the convergence of cystic and hepatic ducts and the proximal portion of the CBD (Fig. 5a). Using

Correspondence: Laurent Palazzo (MD) · 30, rue d'Astorg · 75008 Paris · France . Phone: $0033147421551 \cdot$ E-mail: laurent.palazzo@wanadoo.fr

Bibliography: Endoscopy 2006; 38 (S1): S23-S29 @ Georg Thieme Verlag KG Stuttgart · New York · ISSN 0013-726X · DOI 10.1055/s-2006-946647 this method, the hepatic duct and CBD can be visualized in 95 $100 \%$ of patients [ $1-4]$. It is also mandatory to examine the gall bladder fundus via the transgastric route with the transducer in the gastric antrum.

Standard imaging frequencies of 7.5 and $12 \mathrm{MHz}$ are employed allowing resolution to $1 \mathrm{~mm}$ thus allowing for the detection of very small stones - microlithiasis. However, it is important to start with a lower frequency to ensure that biliary disease at a distance from the transducer is not missed. Slight repositioning of the patient in the semi-prone position may be required to bring the CBD in line with the ultrasound field of view. While it is sometimes difficult to examine the CHD at the level of the hepatic hilum, especially using radial instruments, use of linear scopes facilitates longitudinal views at this level. Another not infrequent, difficulty occurs following endoscopic sphincterotomy or choledochoduodenostomy, where the presence of air within the CBD makes it difficult to examine the peri-ampullary region and $\mathrm{CHD}$, respectively.

\section{Performance of EUS in the detection of choledocholithiasis}

In a prospective and competitive blinded study in a group of patients with CBD obstruction the accuracy of EUS in the diagnosis choledocholithiasis was $100 \%$ (Figs. 3,4) [1]. Moreover, endosonography was significantly more sensitive than transabdominal ultrasonography (US) or CT [1]. The diagnostic performance of EUS for choledocholithiasis is summarized in Table 1 [5-11]. Data from these largely prospective studies include a large number of patients ( $n=1470$ ). EUS demonstrated a high sensitivity (a mean of $93 \%$ ) with an excellent specificity level (> 95\%) in these patients (Table 1 ) who globally, with the exception of one series [8], presented an intermediate risk of CBD stones (20$50 \%$ ). The performance of EUS in recognising choledocholithiasis is not related to stone size or the diameter of the CBD (Figs. 3, 4) $[5,9]$ and high degrees of accuracy are also achieved with linear EUS [12]. In addition, the learning curve required to obtain satisfactory results in diagnosing choledocholithiasis is relatively short as physicians with less than 1 years experience achieve a high degree of skill in this indication [13].

Several studies have compared EUS and ERCP in a blinded fashion (ERCP performed subsequent to EUS and by two different operators $[14,6,10])$. The sensitivity of ERPC was found to be $79-$ $90 \%$ compared to $88-100 \%$ for EUS and false-negative results were observed more frequently with ERCP. It is important to note that the false-negative results with ERCP were due to small stones located within dilated bile ducts, whereas false-negatives for EUS consisted of stones located in the proximal portion of the CHD or the intra-hepatic ducts during the examination. The excellent specificity for EUS in choledocholithiasis has also been shown by Napoleon et al. in patients with suspected CBD stones [15] where 238 patients who were stone-free at EUS were prospectively followed at 1 year. Follow-up revealed that $97 \%$ of patients remained free of CBD stones thus demonstrating the high negative predictive value of EUS [15].

In patients with unexplained acute pancreatitis the use of EUS with high resolution affords an increased chance of detecting micolithiasis - a frequent cause of pancreatitis [16-19]. Here, the role of EUS in relation to ERCP, which is both a diagnostic and 


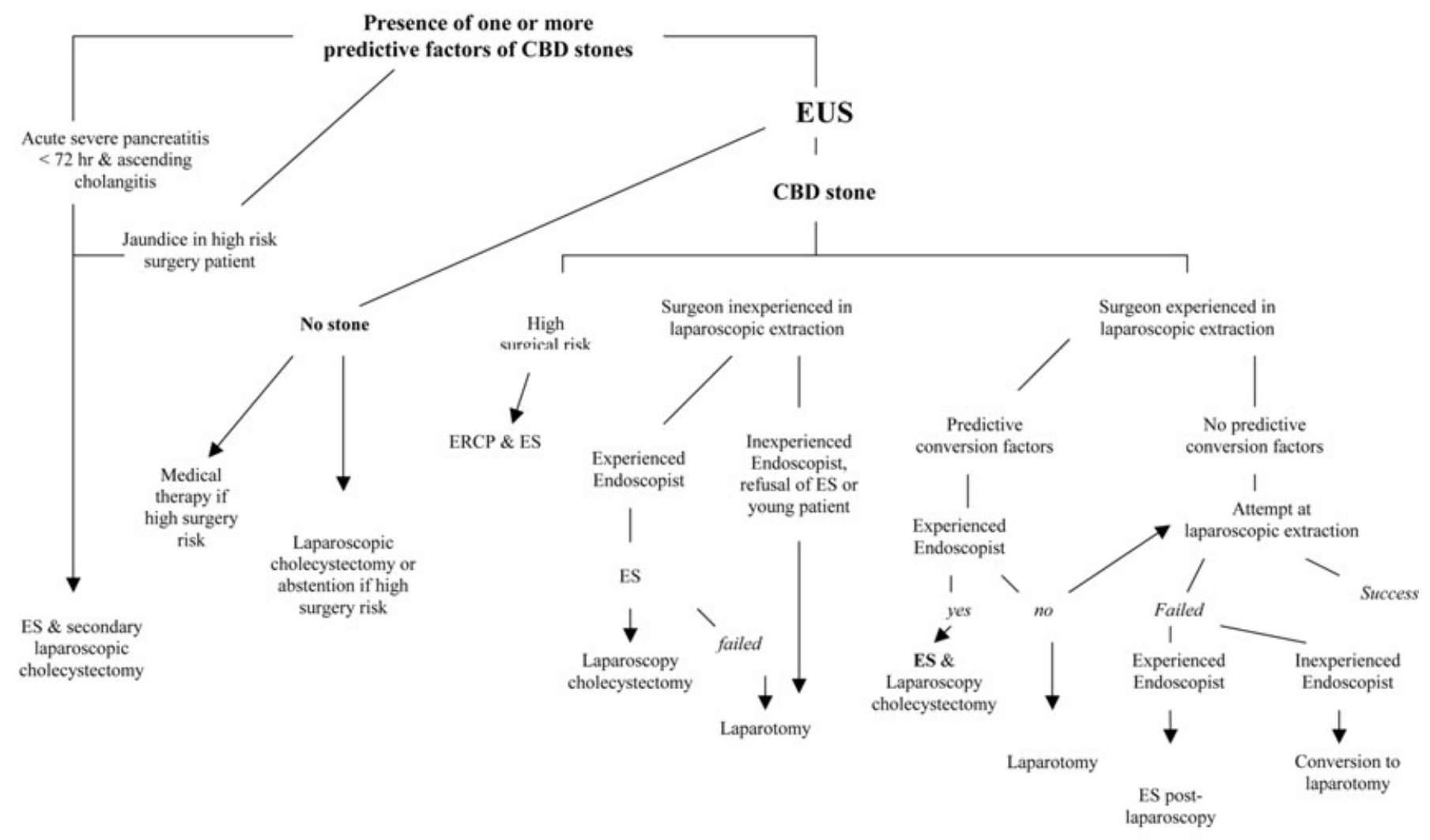

Algorithm Diagnostic and therapeutic algorithm for patients with symptomatic cholecystolithiasis and suspicion of common bile duct (CBD) stones. ES: endocopic sphincterotoma.

therapeutic procedure, is under discussion. Three studies emphasized that EUS should replace ERCP as the first procedure in patients with mild to moderate acute pancreatitis to avoid unnecessary ERCP and thus diminish ERCP-induced morbidity $[17-19,20]$. One interesting study devoted to this situation suggested that the rate of morbidity and mortality could be reduced by systematically using EUS in case of acute pancreatitis followed by ERCP with sphincterotomy when EUS has demonstrated CBD stones [21]. The efficacy and safety of EUS in this indication was confirmed [22] in a prospective randomized study in 140 patients with acute pancreatitis of a suspected biliary origin. Patients were randomised to EUS or ERCP within 24 hours from admission. When EUS detected choledocholithiasis (EUS group), therapeutic ERCP was performed during the same endoscopy session. EUS was successful in all patients in the EUS group, whereas cannulation of the CBD during ERCP was unsuccessful in 10 patients $(14 \%)$ in the ERCP group $(P=0.001)$. Combined percutaneous transabdominal US and ERCP failed to detect CBD stones in 6 patients in the ERCP group and overall morbidity rate was $7 \%$ and $14 \%$ (NS) in the EUS and ERCP groups, respectively [22]. Given the efficacy and relative simplicity of EUS in patients with pancreatitis of suspected biliary origin, it should be proposed as a screening method especially patients with low to moderate risks of a biliary origin. The combination of EUS and eventually ERCP, in the event of finding a CBD stone, during the same session is highly recommended to avoid a subsequent endoscopic session. Whether MRC will become sufficiently accurate for the detection of small stones in this setting remains to be shown.

\section{EUS or magnetic resonance cholangiography?}

The use of non-invasive techniques to detect CBD stones is an appealing option and magnetic resonance cholangiography (MRC) is gaining experience in this indication. MRC is especially interesting in patients with low to intermediate risk of choledocholithiasis (and in those who pose contraindications for sedation endoscopy) where interventional strategies are less likely to be required. However, patients with such risk for CBD stones are more likely to have small stones which may be difficult to detect without EUS (the risk groups for CBD stones are given in Table 2 ). Good comparative data on accuracy of MRC in the detection of choledocholithiasis are to date lacking. A high sensitivity of $100 \%$ with a poorer specificity of $73 \%$ were initially reported using MRC [23] and this was reported to be independent of stone size. However, in a recent study by Kondo et al the sensitivities of EUS, MRC, and CT scan were $100 \%, 88 \%$, and $88 \%$, respectively [24]. The differences between EUS and MRC were largely explained by stone size as the sensitivity of MRC in detecting stones above and below $5 \mathrm{~mm}$ was $100 \%$ and $67 \%$, respectively [24].

\section{Performance of EUS in the detection of gallibladder microlithiasis}

EUS is also excellent in the diagnosis of unrecognised gallbladder microlithiasis with a sensitivity of almost $100 \%$. In patients with a high suspicion of cholelithiasis following two negative transabdominal ultrasounds EUS is the diagnostic tool of choice. The 

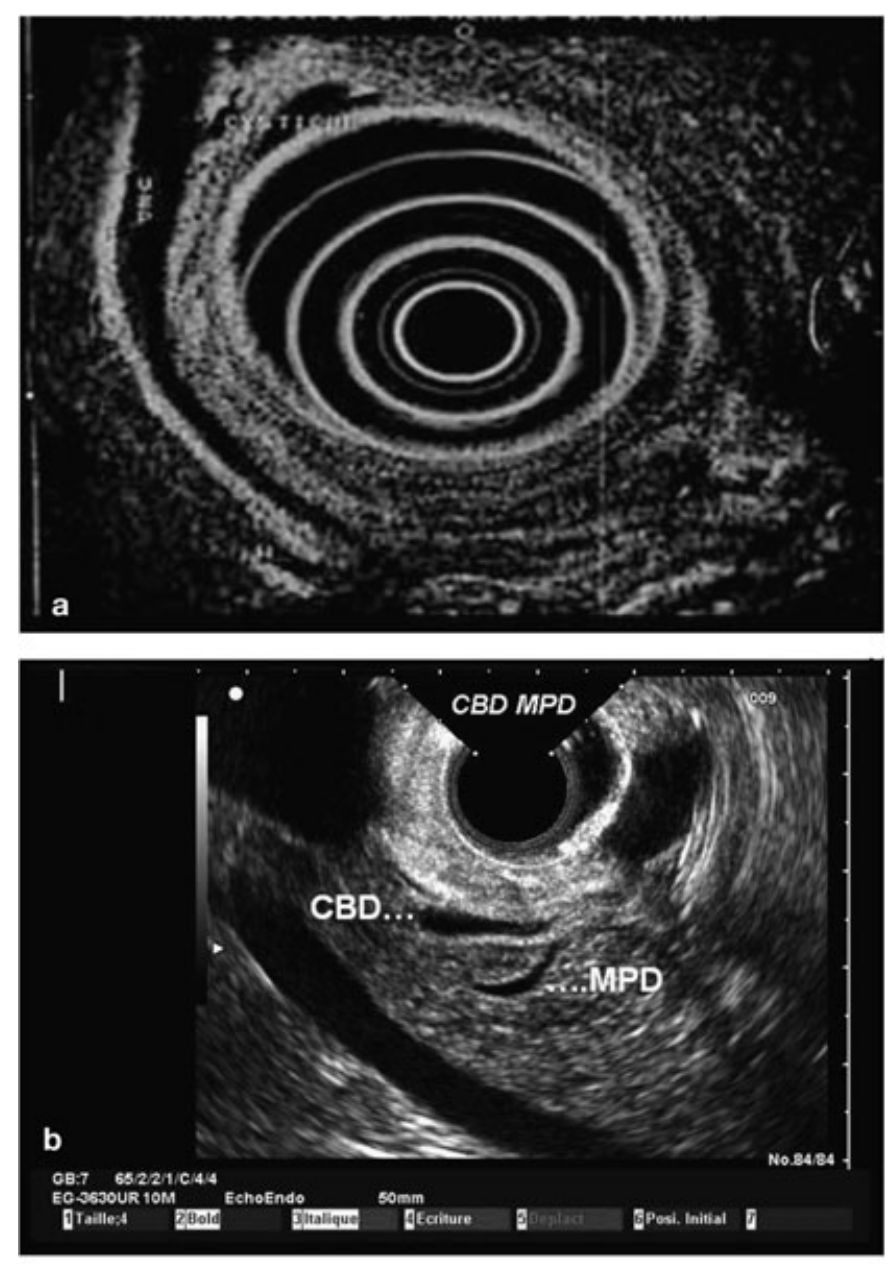

Fig. 1 a Longitudinal section of the common bile duct inside the pancreas with the cystic duct junction proximally and the MPD distally. $\mathbf{b}$ Junction of the common bile duct (CBD) and the main pancreatic duct (MPD) at the level of the ampulla of Vater.

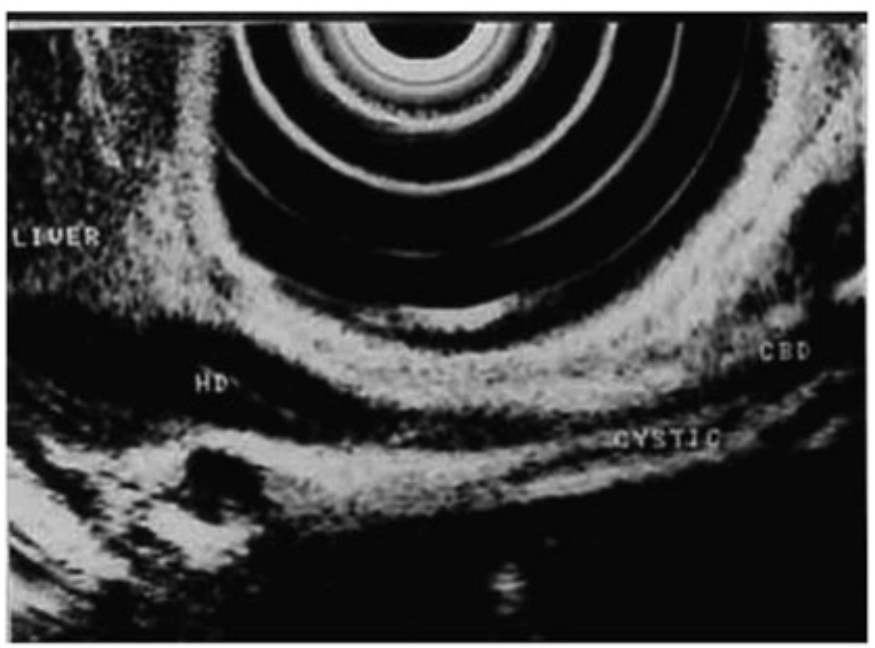

Fig. 2 The transducer is in the duodenal bulb and the common hepatic duct (HD) is visualised below the inflated balloon and the cystic duct junction below the hepatic duct. IVC: inferior vena cava.

value of EUS in such circumstances was underlined in patients with acute pancreatitis, where the sensitivity of EUS was 96\% for the detection of gallbladder microlithiasis compared to $67 \%$ obtained with microscopic examination of aspirated duodenal bile following stimulation by cholecystokinin (Fig. 5) [25]. These results have been subsequently confirmed [26]. Indeed in a recent multicentre prospective study involving 213 patients with acute pancreatitis endosonography was the sole method establishing the diagnosis of biliary pancreatitis in $15 \%$ of patients [27].

\section{EUS prior to laparoscopic cholecystectomy}

The prediction of CBD stones in patients with symptomatic choledocholithiasis may be estimated with excellent precision by
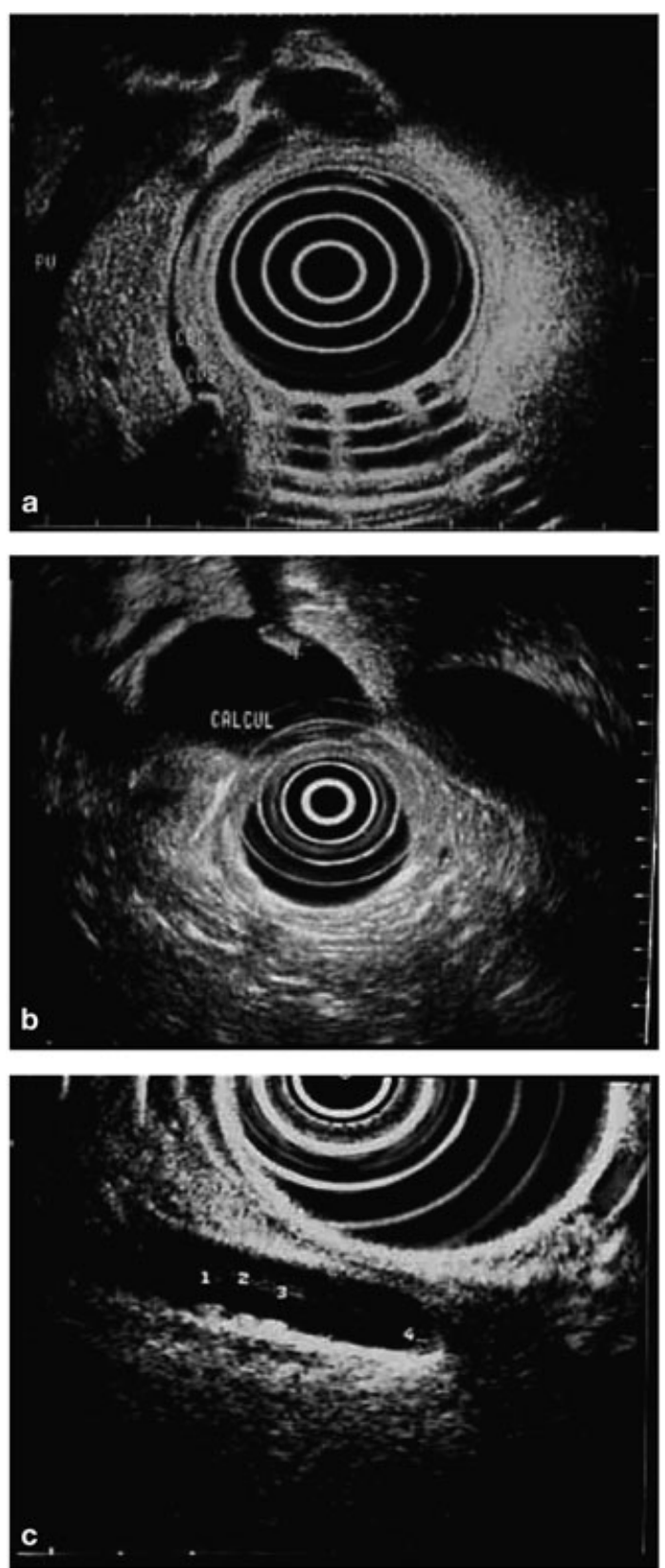

Fig. 3 a Small stone (3 mm) with typical acoustic shadowing (black arrow) in the distal portion of a non-dilated CBD. PV = portal vein. $\mathbf{b}$ Small stone $(5 \mathrm{~mm})$ within a dilated CBD $(18 \mathrm{~mm})$. c Three very small calculi $(1 \mathrm{~mm}$ in size) located within the dependant portion of the lower part of the CBD which is not dilated $(5 \mathrm{~mm})$. 


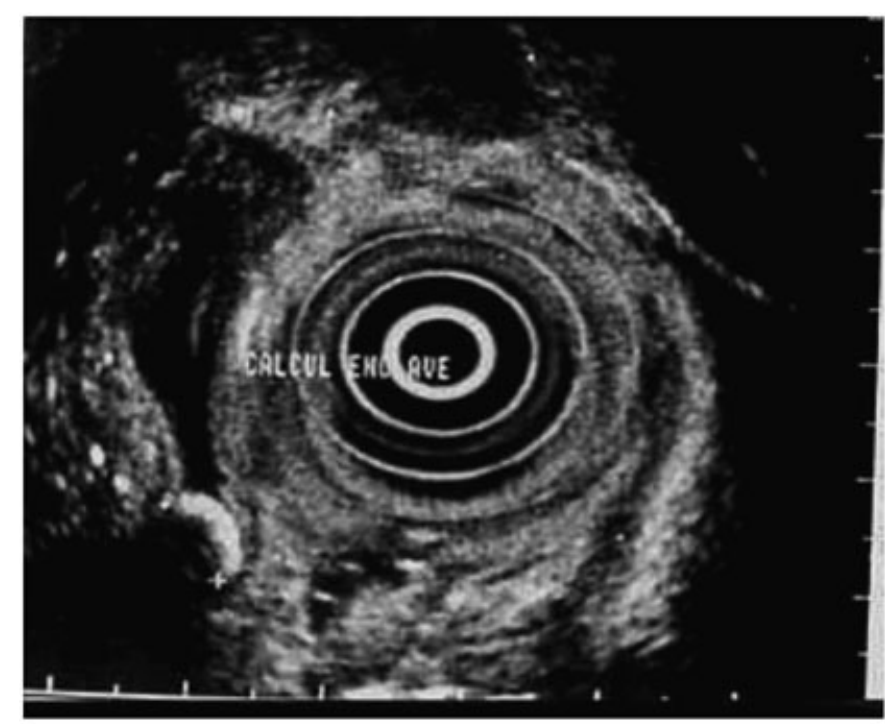

Fig. 4 Small stone (6 $\mathrm{mm}$ in size) impacted in the distal CBD beneath a stenosis of the duct with thickened wall due to cholangitis.

combining a number of clinical, biological and morphological criteria $[28,29]$. Three different risk groups may be determined (Table 2) with risk of finding choledocholithiasis of between 2 to $80 \%$. The probability of finding stones in the CBD of these patients decreases as the period between the onset of symptoms and exploration increases because of spontaneous evacuation of CBD stones. Spontaneous evacuation of CBD stones was estimated to be approximately $21 \%$ as evaluated by EUS and ERCP performed between 6 hours and 27 days, respectively following the onset of symptoms [30]. The spontaneous passage of stones occurred in two-thirds of patients between a period of 6 hours and 3 days but stone migration continued up to 27 days following initial EUS [30]. Thus, even in patients with predictive factors suggesting a high risk of CBD stones, not all have choledocholithiasis at examination cholecystectomy [31]. The delay between symptom onset and exploration should therefore be considered in analysis of patients at risk of CBD stones as the further the delay, the lower the chance of positive results.

It is accepted that patients categorized to the different riskgroups (Table $\mathbf{2}$ ) merit different therapeutic strategies (Table $\mathbf{2}$ and treatment algorithm). In fact, treatment options also depend on local experience of both surgeons and endoscopists and the wishes of the patients; once the advantages, risks and probabilities of success of the different methods have been clearly explained to them [32]:

Patients in the low-risk group may be treated using laparoscopic cholecystectomy without any preoperative examination of the CBD. It seems unreasonable to propose 100 explorations (of whatever kind) of the CBD in order to identify stones in 2 or 3 patients. Some surgeons carry out systematic intra-operative opacification in order to examine the anatomy of the biliary tree and/or to verify a patent CBD.

Those with a clearly identified high-risk may be selected at the outset for cholecystectomy using classical laparotomy. This is rarely indicated when the diagnosis of choledocholithiasis is certain following trans-abdominal ultrasound, and when the surgeon is not skilled in laparoscopic extraction of CBD stones and the patient is young and/or does not wish to have an endoscopic sphincterotomy. Endoscopic retrograde opacification may be performed for diagnosis and treatment in the presence of acute ascending cholangitis or in the case of severe acute pancreatitis observed within the first 72 hours; the same applies to poor candidates for surgery (see algorithm). In other cases, EUS may be proposed particularly if several days have elapsed between the onset of symptoms and treatment in order to verify CBD patency. In patients with persistent $\mathrm{CBD}$ stones, EUS can determine the size, location and number of stones, whether they are impacted or mobile, the diameter of the CBD and cystic ducts, type of the cystic duct implantation (normal or deep) and finally the state of the gallbladder (acute endosonographic severe cholecystitis with cholecysto-bulbar fistula is a contraindication to laparoscopic cholecystectomy). The above elements are helpful to the surgeon in selecting the best extraction strategy. If a cause other than stones is found at EUS such as cholangiocarcinoma, ampullary or pancreatic tumours, endosonographic loco-regional extension can also be performed [14].

For patients at intermediate-risk, the most appropriate current strategy comprises preoperative EUS possibly followed by either endoscopic sphincterotomy during the same session in the event of CDB stones or laparoscopic extraction if the surgeon is skilled in this manner and in the absence of factors predictive of conversion to laparotomy (see algorithm).

Table 1 Performance of EUS in the detection of choledocholithiasis

\begin{tabular}{|c|c|c|c|c|c|c|}
\hline Author & Study design & No. patients & $\begin{array}{l}\text { Frequency of } \\
\text { choledocholithiasis }\end{array}$ & $\begin{array}{l}\text { Sensitivity } \\
\%\end{array}$ & $\begin{array}{l}\text { Specificity } \\
\%\end{array}$ & $\begin{array}{l}\text { Diagnostic } \\
\text { accuracy \% }\end{array}$ \\
\hline Amouyal, 1994 [5] & Prospective/Blind & 62 & $32(52 \%)$ & 97 & 100 & 98 \\
\hline Shim, 1995 [6] & Prospective/Blind & 132 & $28(21 \%)$ & 89 & 100 & 97 \\
\hline Palazzo, 1995 [7] & Retrospective/Blind & 422 & $152(36 \%)$ & 95 & 98 & 96 \\
\hline Prat, 1996 [8] & Prospective/Blind & 119 & $78(66 \%)$ & 93 & 97 & 95 \\
\hline Sugiyama, 1997 [9] & Prospective/Blind & 142 & $51(36 \%)$ & 96 & 100 & 99 \\
\hline Norton, 1997 [10] & Prospective/Blind & 50 & $24(48 \%)$ & 88 & 96 & 92 \\
\hline Canto, 1998 [11] & Prospective/Blind & 64 & $19(30 \%)$ & 84 & 95 & 92 \\
\hline
\end{tabular}


Table 2 Risk of presence of common bile duct (CBD) stones in patients with suspected choledocholithiasis according to clinical, biological and morphological criteria

\begin{tabular}{|c|c|c|c|c|}
\hline & $\begin{array}{l}\text { Chance of } \\
\text { CBD stones }\end{array}$ & Clinical parameters & Biological parameters & CBD diameter \\
\hline Low risk & $2-3 \%$ & no associated clinical history & normal & $\leq 7 \mathrm{~mm}$ \\
\hline Intermediate risk & $20-50 \%$ & $\begin{array}{l}\text { acute ascending cholangitis } \\
\text { pancreatitis }\end{array}$ & $\begin{array}{l}\uparrow \mathrm{ALP} \leq \text { twice } \mathrm{UPL}^{*} \\
\uparrow \mathrm{GGT} \\
\uparrow \mathrm{ALT} / \mathrm{or} \uparrow \mathrm{AST}\end{array}$ & $8-10 \mathrm{~mm}$ \\
\hline High risk & $50-80 \%$ & $\begin{array}{l}\text { acute ascending cholangitis } \\
\text { jaundice }\end{array}$ & $\uparrow \mathrm{ALP}>$ twice $\mathrm{UNL}^{*}$ & $>10 \mathrm{~mm}$ \\
\hline
\end{tabular}

*UPL: the upper normal value

ALP: alkaline phosphatase; AST: aspartate transaminase; ALT: alanine transaminans
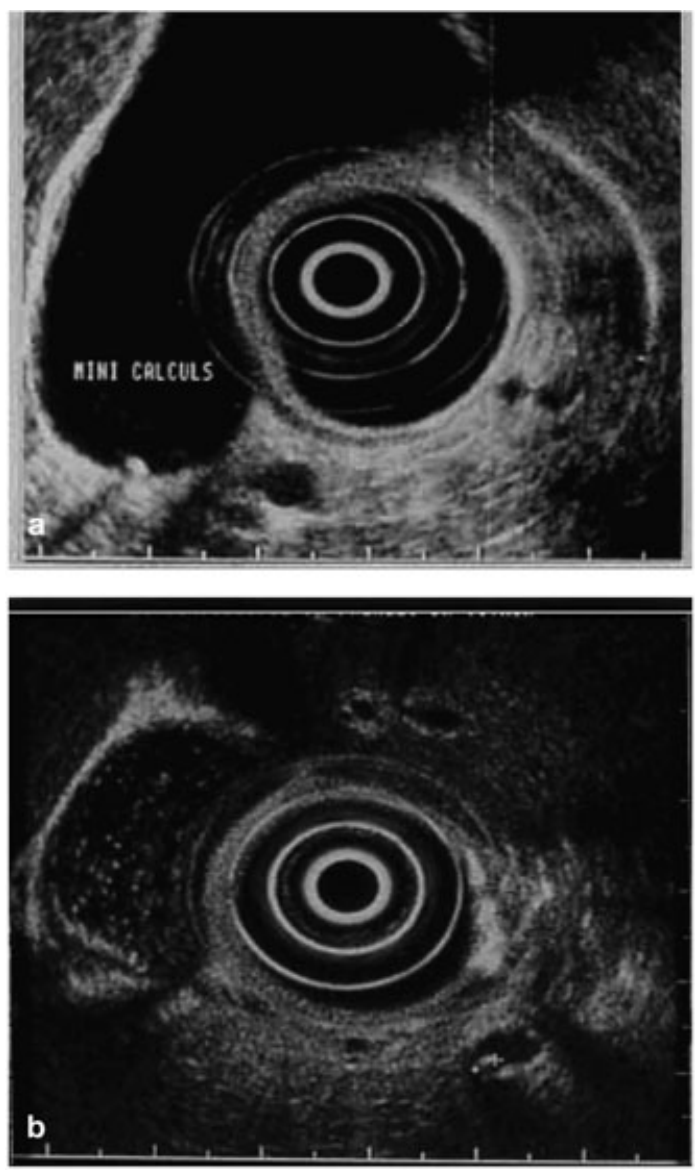

Fig. 5 a. Microlithiasis $(1 \mathrm{~mm})$ in the neck of the gallbladder. $\mathbf{b}$. Micro-lithiasis of the gallbladder with typical "stared sky" aspect.

\section{EUS after Cholecystectomy}

Residual or recurrence lithiasis of the CBD following cholecystectomy occurs in $1-5 \%$ of cases [33]. In routine practice, such a situation is suspected when there is either biliary colic associated with transient abnormalities in the hepatic or pancreatic blood tests or persistent abnormalities in blood tests with or without a dilated CBD at trans-abdominal ultrasound. This situation is quite frequent in daily practice and is complicated by the fact that the main differential diagnosis, i.e. sphincter of Oddi dys- function (SOD), is impossible to differentiate on clinical, biochemical or evolutionary criteria.

Residual or recurrent lithiasis is potentially serious if not recognised and untreated due to the risk of ascending cholangitis or severe pancreatitis. It is therefore important to diagnose it when it is suspected. SOD on the other hand is different in that the majority of complications stem from diagnostic efforts using ERCP, especially if endoscopic sphincterotomy is performed $[34,35-37]$ (the latter of which is necessary in the event of the discovery of a dilated CBD in order avoid misdiagnosing small stones not seen at simple injection of contrast medium [38]) or using sphincter of Oddi manometry. In fact, in case of SOD, ERCP and manometry are accompanied by a serious risk of acute pancreatitis [34-37]. The paradox in this situation is that endoscopic sphincterotomy is the treatment of choice in terms of efficacy, morbidity and death rate with respect to residual or recurrent lithiasis [39], while this is an effective but also very dangerous treatment (about $20 \%$ of acute pancreatitis) in cases of SOD [34-37]. Thus, caution should be applied prior to endoscopic sphincterotomy where the diagnosis of residual lithiasis and SOD is not apparent. EUS is clearly the examination of choice in this delicate situation and its use appears even clearer in patients at high risk of SOD, i.e. in young subjects with narrow CBD and no evidence of ascending cholangitis.

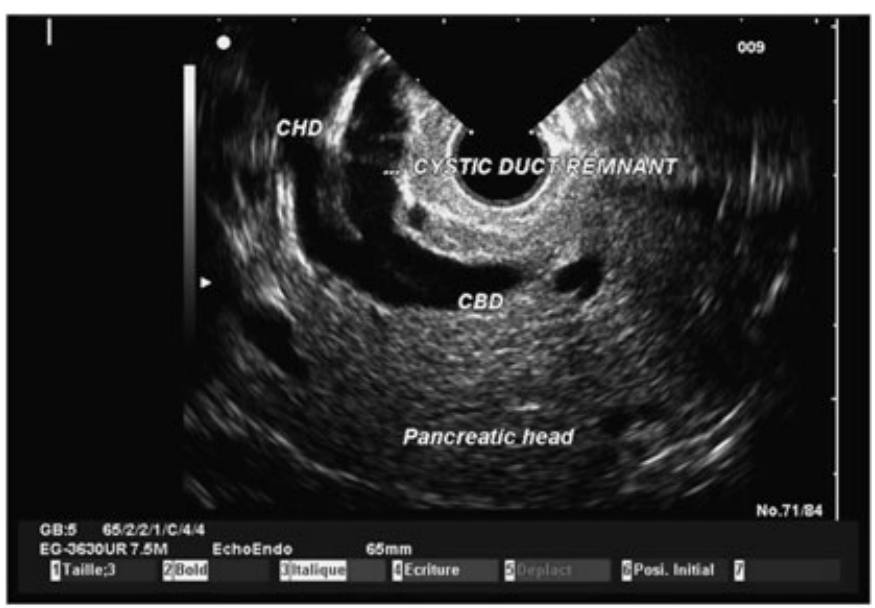

Fig. 6 Dilatation of the intra-pancreatic portion of the CBD (which measures $7 \mathrm{~mm}$ ). Note that the common hepatic duct is dilated (CHD) as well as the remnant of the cystic duct. 
As regards MRCP, its role in this sub-group of patients with thin bile ducts is worthy of evaluation and prospective comparison with EUS (see above).

\section{Asymptomatic dilatation of the common bile duct}

Although in a routine clinical setting the significance of a dilated $\mathrm{CBD}$ in the absence of symptoms pertaining to biliary or pancreatic disease is extremely frequent, little research data is available on this subject. Several mechanisms may result in dilatation of the extra-hepatic bile ducts including strictly benign disorders post cholecystectomy (Fig.6), dilatation secondary to certain drugs (opiates...) or incidental anomalous junction of the pancreaticobiliary duct (AUPBD) - where follow-up explorations are indeed not required. Indeed, although many experts felt that a large CBD diameter was physiological in the elderly and while the diameter increases significantly with age, $98 \%$ of all ducts remained below 6 to $7 \mathrm{~mm}$, the commonly accepted upper range of normal, in a large prospective series of asymptomatic patients ( $n=1018$ ) aged 60 to 94 years (analysis performed using transabdominal US) [40]. However, a number of situations exist where "significant" pathologies results in an asymptomatic dilated CBD including asymptomatic choledocholithiasis, malignant and benign (e.g., sclerosing cholangitis) strictures and choledochal cysts. Indeed, asymptomatic choledocholithiasis has been estimated to be as high as $19 \%$ in some surgical series [41] - thus underlying the need for thorough CBD exploration in patients undergoing laparoscopic cholecystectomy (as discussed above). Recently, Kim et al. [42] studied 77 patients with an asymptomatic internal CBD diameter $>7 \mathrm{~mm}$ at US and without a definite causative lesion on the latter. Of these, 49 underwent ERCP and 28 underwent follow-up US or CT instead of ERCP. Patients with increased bilirubin or with a previous history of upper abdominal surgery including cholecystectomy were excluded. Follow-up examinations revealed: a) ERCP: no lesion in 20 patients (41\%), juxtapapillary duodenal diverticulum (JDD) in 11 (23\%), benign stricture in ten (20\%), distal CBD mass in two (4\%), choledochal cyst in two (4\%), anomalous junction of the pancreaticobiliary duct (AUPBD) in two (4\%), and choledochal cyst with AUPBD in two (4\%). There were no differences in age or in alkaline phosphatase or gamma-glutamyl transpeptidase levels between the patients who had causative lesions revealed at ERCP and those who did not; b) among the 28 patients who did not undergo ERCP, the CBD returned to normal in 12 and eight had no change in CBD diameter on follow-up US. Among eight patients who underwent $\mathrm{CT}$, there were four with normal findings, one with JDD, and three with suspected choledochal cysts [42]. Thus a significant cause of biliary tract lesions in asymptomatic adults with dilatation of the CBD can be found and certain such as choledochal cysts require careful surveillance and preventive surgery [43]. Most often, a dilated CBD in such circumstances results from an incidental discovery at US or CT - performed for another unrelated reason. While these examinations in themselves can help in ruling out obvious causes (e.g., early malignant obstruction or a large asymptomatic stone) endosonography appears to be the method of choice as it capable of providing a diagnosis in almost all cases; In fact, EUS was found to provide an accurate explanation for CBD dilatation from an unexplained cause in 70 of the 76 patients (92\%) [44].

\section{Conclusions}

Despite the development of MRCP and the laparoscopic extraction of CBD stones, the place of EUS in the diagnosis of CBD stones remains important. The examination combines the best performance and almost zero morbidity and unlike EUS for other indications, the results in relation to choledocholithiasis depend little on the experience of the operator. Its role in relation to other diagnostic techniques depends principally on the environment (experience of the surgeon and interventional endoscopist) and the circumstances of the diagnosis. The main advantages of EUS are its sensitivity and specificity even in patients with small calculi in a non-dilated CBD. In the future however, other imaging modalities may challenge EUS. The role of EUS versus that of ERCP has been correctly defined; a comparison with MRC needs to be evaluated prospectively in a controlled group of patients who pose serious frequent diagnostic dilemmas, i.e. those with a non-dilated CBD and small stones, because these are patients who represent difficult therapeutic problems in terms of feasibility for laparoscopic extraction and in terms of the potential morbidity of laparoscopic extraction and endoscopic sphincterotomy. Finally, when EUS is chosen as the imaging modality to identify CBD stones, it seems logical to perform ERCP during the same session to enable therapeutic extraction. Thus, training in both biliary EUS and therapeutic ERCP seems to be a promising goal for young endoscopists who want to specialize in interventional endoscopy.

\section{References}

${ }^{1}$ Amouyal P, Palazzo L, Amouyal G, Ponsot P, Mompoint D, Vilgrain V, Gayet B, Flejou JF, Paolaggi JA. Endosonography: promising method for diagnosis of extrahepatic cholestasis. Lancet 1989; 2: 1195-1198

2 Dancygier H, Nattermann C. The role of endoscopic ultrasonography in biliary tract disease: obstructive jaundice. Endoscopy 1994; 26 : $800-$ 802

${ }^{3}$ Snady H, Cooperman A, Siegel J. Endoscopic ultrasonography compared with computed tomography with ERCP in patients with obstructive jaundice or small peri-pancreatic mass. Gastrointest Endosc 1992; 38: $27-34$

4 Palazzo L. L'écho-endoscopie bilio-pancréatique. In: Palazzo L, Roseau, G, ed. L'écho-endoscopie digestive Paris: Masson, 1992: 53-100

${ }^{5}$ Amouyal P, Amouyal G, Levy P, Tuzet S, Palazzo L, Vilgrain V, Gayet B, Belghiti J, Fekete F, Bernades P. Diagnosis of choledocholithiasis by endoscopic ultrasonography. Gastroenterology 1994; 106: 1062 - 1067

${ }^{6}$ Shim CS, Joo JH, Park CW, Kim YS, Lee JS, Lee MS, Hwang SG. Effectiveness of endoscopic ultrasonography in the diagnosis of choledocholithiasis prior to laparoscopic cholecystectomy. Endoscopy 1995; 27: $428-432$

7 Palazzo L, Girollet PP, Salmeron M, Silvain C, Roseau G, Canard JM, Chaussade S, Couturier D, Paolaggi JA. Value of endoscopic ultrasonography in the diagnosis of common bile duct stones: comparison with surgical exploration and ERCP. Gastrointest Endosc 1995; 42: 225-231

8 Prat F, Amouyal G, Amouyal P, Pelletier G, Fritsch J, Choury AD, Buffet C, Etienne JP. Prospective controlled study of endoscopic ultrasonography and endoscopic retrograde cholangiography in patients with suspected common-bileduct lithiasis. Lancet 1996; 347: 75 - 79

${ }^{9}$ Sugiyama M, Atomi Y. Endoscopic ultrasonography for diagnosing choledocholithiasis: a prospective comparative study with ultrasonography and computed tomography. Gastrointest Endosc 1997; 45: $143-146$

${ }^{10}$ Norton SA, Alderson D. Prospective comparison of endoscopic ultrasonography and endoscopic retrograde cholangiopancreatography in the detection of bile duct stones. Br J Surg 1997; 84: 1366-1369 
${ }^{11}$ Canto MI, Chak A, Stellato T, Sivak MVJr. Endoscopic ultrasonography versus cholangiography for the diagnosis of choledocholithiasis. Gastrointest Endosc 1998; 47: 439-448

${ }^{12}$ Kohut M, Nowakowska-Dulawa E, Marek T, Kaczor R, Nowak A. Accuracy of linear endoscopic ultrasonography in the evaluation of patients with suspected common bile duct stones. Endoscopy 2002; 34: 299-303

${ }^{13}$ Denis BJ, Bas V, Goudot C, Frederic M, Bigard MA, Gaucher P. Accuracy of endoscopic ultrasonography for diagnosis of common bile duct stones (Abstract). Gastroenterology 1993; 104: A 358

${ }^{14}$ Burtin P, Palazzo L, Canard JM, Person B, Oberti F, Boyer J. Diagnostic strategies for extrahepatic cholestasis of indefinite origin: endoscopic ultrasonography or retrograde cholangiography? Results of a prospective study. Endoscopy 1997; 29: 349-355

${ }^{15}$ Napoleon B, Dumortier J, Keriven-Souquet O, Pujol B, Ponchon T, Souquet JC. Do normal findings at biliary endoscopic ultrasonography obviate the need for endoscopic retrograde cholangiography in patients with suspicion of common bile duct stone? A prospective follow-up study of 238 patients. Endoscopy 2003; 35: $411-415$

${ }^{16}$ Frossard JL, Sosa-Valencia L, Amouyal G, Marty O, Hadengue A, Amouyal P. Usefulness of endoscopic ultrasonography in patients with "idiopathic" acute pancreatitis. Am J Med 2000; 109: 196-200

${ }^{17}$ Liu CL, Lo CM, Chan JK, Poon RT, Fan ST. EUS for detection of occult cholelithiasis in patients with idiopathic pancreatitis. Gastrointest Endosc 2000; 51: $28-32$

${ }^{18}$ Coyle WJ, Pineau BC, Tarnasky PR, Knapple WL, Aabakken L, Hoffman BJ, Cunningham JT, Hawes RH, Cotton PB. Evaluation of unexplained acute and acute recurrent pancreatitis using endoscopic retrograde cholangiopancreatography, sphincter of Oddi manometry and endoscopic ultrasound. Endoscopy 2002; 34: 617 -623

${ }^{19}$ Chak A, Hawes RH, Cooper GS, Hoffman B, Catalano MF, Wong RC, Herbener TE, Sivak MVJr. Prospective assessment of the utility of EUS in the evaluation of gallstone pancreatitis. Gastrointest Endosc 1999; 49: $599-604$

${ }^{20}$ Sugiyama M, Atomi Y. Acute biliary pancreatitis: the roles of endoscopic ultrasonography and endoscopic retrograde cholangiopancreatography. Surgery 1998; 124: $14-21$

${ }^{21}$ Prat F, Edery J, Meduri B, Chiche R, Ayoun C, Bodart M, Grange D, Loison F, Nedelec P, Sbai-Idrissi MS, Valverde A, Vergeau B. Early EUS of the bile duct before endoscopic sphincterotomy for acute biliary pancreatitis. Gastrointest Endosc 2001; 54: 724 - 729

${ }^{22}$ Liu CL, Fan ST, Lo CM, Tso WK, Wong Y, Poon RT, Lam CM, Wong BC, Wong J. Comparison of early endoscopic ultrasonography and endoscopic retrograde cholangiopancreatography in the management of acute biliary pancreatitis: a prospective randomized study. Clin Gastroenterol Hepatol 2005; 3: $1238-1244$

${ }^{23}$ de Ledinghen V, Lecesne R, Raymond JM, Gense V, Amouretti M, Drouillard J, Couzigou P, Silvain C. Diagnosis of choledocholithiasis: EUS or magnetic resonance cholangiography? A prospective controlled study. Gastrointest Endosc 1999; 49: 26-31

${ }^{24}$ Kondo S, Isayama H, Akahane M, Toda N, Sasahira N, Nakai Y, Yamamoto N, Hirano K, Komatsu Y, Tada M, Yoshida H, Kawabe T, Ohtomo K, Omata M. Detection of common bile duct stones: comparison between endoscopic ultrasonography, magnetic resonance cholangiography, and helical-computed-tomographic cholangiography. Eur J Radiol 2005; 54: $271-275$

25 Dahan P, Andant C, Levy P, Amouyal P, Amouyal G, Dumont M, Erlinger S, Sauvanet A, Belghiti J, Zins M, Vilgrain V, Bernades P. Prospective evaluation of endoscopic ultrasonography and microscopic examination of duodenal bile in the diagnosis of cholecystolithiasis in 45 patients with normal conventional ultrasonography. Gut 1996; 38: $277-281$

${ }^{26}$ Dill JE, Hill S, Callis J, Berkhouse L, Evans P, Martin D, Palmer ST. Combined endoscopic ultrasound and stimulated biliary drainage in cholecystitis and microlithiasis-diagnoses and outcomes. Endoscopy 1995; 27: 424-427

${ }^{27}$ Levy P, Boruchowicz A, Hastier P, Pariente A, Thevenot T, Frossard JL, Buscail L, Mauvais F, Duchmann JC, Courrier A, Bulois P, Gineston JL, Barthet M, Licht H, O'Toole D, Ruszniewski P. Diagnostic criteria in predicting a biliary origin of acute pancreatitis in the era of endoscopic ultrasound: multicentre prospective evaluation of 213 patients. Pancreatology 2005; 5: 450-456

${ }^{28}$ Cotton PB, Baillie J, Pappas TN, Meyers WS. Laparoscopic cholecystectomy and the biliary endoscopist. Gastrointest Endosc 1991; 37: 94-7
${ }^{29}$ Cotton PB. Endoscopic retrograde cholangiopancreatography and laparoscopic cholecystectomy. Am J Surg 1993; 165: 474-478

${ }^{30}$ Frossard JL, Hadengue A, Amouyal G, Choury A, Marty O, Giostra E, Sivignon F, Sosa L, Amouyal P. Choledocholithiasis: a prospective study of spontaneous common bile duct stone migration. Gastrointest Endosc 2000; 51: 175-179

${ }^{31}$ Meroni E, Bisagni P, Bona S, Fumagalli U, Zago M, Rosati R, Malesci A. Pre-operative endoscopic ultrasonography can optimise the management of patients undergoing laparoscopic cholecystectomy with abnormal liver function tests as the sole risk factor for choledocholithiasis: a prospective study. Dig Liver Dis 2004; 36: $73-77$

32 Binmoeller KF, Soehendra N, Liguory C. The common bile duct stone: time to leave it to the laparoscopic surgeon. Endoscopy 1994; 26: 315 - 9

${ }^{33}$ Hermann RE. The spectrum of biliary stone disease. Am J Surg 1989; 158: $171-173$

${ }^{34}$ Huibregtse K. Complications of endoscopic sphincterotomy and their prevention. N Engl J Med 1996; 335: 961 - 963

${ }^{35}$ Chen YK, Foliente RL, Santoro MJ, Walter MH, Collen MJ. Endoscopic sphincterotomy-induced pancreatitis: increased risk associated with nondilated bile ducts and sphincter of Oddi dysfunction. Am J Gastroenterol 1994; 89: $327-333$

${ }^{36}$ Smithline A, Silverman W, Rogers D, Nisi R, Wiersema M, Jamidar P, Hawes R, Lehman G. Effect of prophylactic main pancreatic duct stenting on the incidence of biliary endoscopic sphincterotomy-induced pancreatitis in high-risk patients. Gastrointest Endosc 1993; 39: $652-657$

37 Sherman S, Ruffolo TA, Hawes RH, Lehman GA. Complications of endoscopic sphincterotomy. A prospective series with emphasis on the increased risk associated with sphincter of Oddi dysfunction and nondilated bile ducts. Gastroenterology 1991; 101: 1068 - 1075

${ }^{38}$ French Consensus Conference on Acute Pancreatitis. Conclusions and Recommendations. Paris, France, 25 - 26 January 2001. Eur J Gastroenterol Hepatol 2001; 13 Suppl 4: S1 - 13

39 Vaira D, D’Anna L, Ainley C, Dowsett J, Williams S, Baillie J, Cairns S, Croker J, Salmon P, Cotton P et al. Endoscopic sphincterotomy in 1000 consecutive patients. Lancet 1989; 2: $431-434$

40 Perret RS, Sloop GD, Borne JA. Common bile duct measurements in an elderly population. J Ultrasound Med 2000; 19: 727 - 730; quiz 731

${ }^{41}$ Montariol T, Msika S, Charlier A, Rey C, Bataille N, Hay JM, Lacaine F, Fingerhut A. Diagnosis of asymptomatic common bile duct stones: preoperative endoscopic ultrasonography versus intraoperative cholangiography - a multicenter, prospective controlled study. French Associations for Surgical Research. Surgery 1998; 124: 6-13

42 Kim JE, Lee JK, Lee KT, Park DI, Hyun JG, Paik SW, Rhee JC, Choi KW, Lim $\mathrm{JH}$. The clinical significance of common bile-duct dilatation in patients without biliary symptoms or causative lesions on ultrasonography. Endoscopy 2001; 33: 495-500

${ }^{43}$ Kianmanesh R, Regimbeau JM, Belghiti J. [Pancreato-biliary maljunctions and congenital cystic dilatation of the bile ducts in adults]. J Chir (Paris) 2001; 138: 196-204

${ }^{44}$ Songur Y, Temucin G, Sahin B. Endoscopic ultrasonography in the evaluation of dilated common bile duct. J Clin Gastroenterol 2001; 33: $302-305$ 